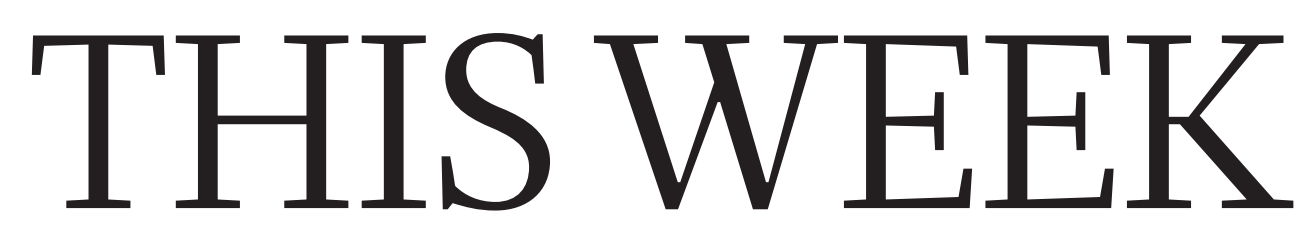

EDITORIALS

CONSERVATION FOrest-protection scheme must do more to respect rights $\mathbf{p . 3 9 0}$
WORLD VIEW Reviewers should stop asking authors for more experiments $\mathbf{p . 3 9 1}$
SHARPEN UP Phase contrast

X-ray imaging shows

beetle at its best $\mathbf{p . 3 9 2}$

\title{
A watchdog with bite
}

\section{The world must strengthen the ability of the International Atomic Energy Agency to make independent assessments of nuclear safety.}

$\mathrm{I}$ $\mathrm{n}$ a recent press conference at the International Atomic Energy Agency (IAEA) in Vienna, a reporter asked a simple question. Chronicling the ongoing nuclear emergency at the Fukushima Daiichi nuclear power plant in Japan, the agency's website consistently referred to "white smoke" rising from the reactors. Why, the journalist asked, did the agency put quotations around the words white smoke?

Denis Flory, the agency's head of nuclear safety and security, said the term arose from lengthy discussions with Japan's nuclear regulator over how to translate the phrase “白い湯気のような煙” (shiroi yuge noyouna kemuri), the words used in official Japanese statements. "We got the answer that it meant 'white smoke', so this is why we use 'white smoke," he said flatly.

Even by the strict standards of international organizations, the IAEA chooses its words carefully. As the globe's nuclear watchdog, it must simultaneously pronounce on a nation's nuclear programme while being careful not to accuse the country of wanting to develop weapons. Its statements are sometimes cryptic, but they are vital for upholding the delicate Nuclear Non-Proliferation Treaty, which is designed to halt the spread of nuclear weapons.

In the latest nuclear emergency in Japan, however, the IAEA's agonizing over its choice of words has not helped to allay public fears or clarify the situation at the reactors. As illustrated by its derivative use of the term 'white smoke', the agency has been reluctant to deviate even slightly from information delivered by the Japanese government. Its press conferences have been rapid-fire deliveries of temperatures, pressures and radiation readings handed to them by government sources, often with little context.

The agency has good reason to avoid annoying Japan, which is one of 35 members of the board of governors that oversees the IAEA and its budget. Because of the security role played by the organization, these nations have kept the IAEA on a short leash. In the area of nuclear safety, even the rating of a nuclear emergency is out of its hands: individual nations, not the IAEA, judge the severity of an accident.

Nuclear accidents are politically and commercially sensitive events, and it is understandable that countries do not want to cede control of their management to an international body. And nor should they: plant operators are often the best qualified to handle an emergency, and nations must take the responsibility for protecting their citizens.

Yet these nations, and the public at large, would be better served by an IAEA more able to deliver frank and independent assessments of nuclear crises as they unfold. In the aftermath of Fukushima, statements from the Japanese government were often confused. It initially rated the event as an "accident with wider consequences", and then upgraded it to a Chernobyl-scale event a month later, raising anxiety across the country. Moreover, far more severe assessments consistently came from others on the ground, notably the US Nuclear Regulatory Commission. An impartial and authoritative international voice would have been invaluable to avoid at least some of this confusion.

Next month, the IAEA will hold a conference of ministers to discuss lessons to be learned from the Fukushima accident (see page 397). The countries should give the IAEA an explicit mandate, and the necessary resources, to deliver its own safety assessments, both in times of crisis and during the normal operation of nuclear power plants. This

"The public would be better served by an IAEA more able to deliver frank and independent assessments of nuclear crises as they unfold."

In the case of Fukushima Daiichi, an IAEA acting in this way might have strengthened the Japanese position. Japan was criticized in the first days of the crisis for providing too little information on conditions at the plant. An IAEA assessment, based on independent data, could have provided backing for the Japanese decision to rapidly evacuate the surrounding population. It could have provided some reassurance to a panicked population that the government knew what it was doing.

As long as there is nuclear power, there will be the risk of a nuclear emergency. Giving the IAEA the rights and means to pursue a safety agenda cannot prevent such events, but it can reduce their likelihood and strengthen the world's response.

\section{A united front}

\section{Pharmaceutical firms should come clean to tackle drug contamination.}

W hen biotechnology company Genzyme announced the presence of a contaminating virus at its drug-manufacturing plant in Allston, Massachusetts, in 2009, patients were told not to worry. Only a small stockpile of uncontaminated drugs existed, but the company said that it would resume production within two months.

Two years and a host of manufacturing problems later, Genzyme still cannot supply enough of its treatment for Fabry's disease, a rare and potentially lethal enzyme deficiency. Genzyme's replacementenzyme drug, Fabrazyme, which is made at the Allston plant, has been rationed since 2009 so that patients receive smaller doses than initially 